\title{
A long term follow up of 15 patients with arrhythmogenic right ventricular dysplasia
}

\author{
CARINA BLOMSTRÖM-LUNDQVIST, * KARL-GÖRAN SABEL, \\ S BERTIL OLSSON
}

From the Division of Cardiology, Medical Department I, Sahlgrenska Hospital, and the ${ }^{\star}$ Section of Paediatric Cardiology, Department of Paediatrics, Östra Hospital, Gothenburg, Sweden

SUMMARY The clinical course in 15 patients with features consistent with arrhythmogenic right ventricular dysplasia is described. At referral seven patients had abnormal physical findings, nine had abnormal electrocardiograms with non-specific right-sided abnormalities, and seven patients had increased heart size or prominent right ventricles on chest $x$ ray. During long term follow up (mean 8.8 years, range 1.5 to 28 years) 11 patients had abnormal physical findings, 11 had electrocardiographic changes, and nine had increased heart size. Recurrent sustained right ventricular tachycardia was the most common arrhythmia (10 patients). Two patients experienced ventricular fibrillation. Seven patients suffered from over 10 episodes of ventricular tachycardia, nine required cardioversions, and 10 patients had associated serious symptoms such as syncope, severe hypotension, or cardiac arrest. Four patients required operation to correct the arrhythmia and three patients developed right heart failure. Two out of three deaths were sudden.

These data suggest that in arrhythmogenic right ventricular dysplasia right ventricular abnormalities may be progressive and that the condition may affect the left ventricle. The course of the ventricular arrhythmias was highly variable and could not be predicted in individual patients. The potential for lethal ventricular arrhythmias is evident and warrants intensive diagnostic efforts to identify patients with adverse prognostic features.

In 1977 Fontaine et al described a previously unrecognised form of cardiomyopathy affecting the right ventricle. They called this arrhythmogenic right ventricular dysplasia. ${ }^{1}$ The syndrome is characterised by episodes of ventricular tachycardia with a QRS configuration that is typical of left ventricular delay, the presence of ventricular post-excitation waves and global or regional wall motion abnormalities of the right ventricle. ${ }^{2}$ The right ventricular muscle is partially or totally replaced by adipose and fibrous tissue. ${ }^{3}$

Long term follow up of patients with arrhythmogenic right ventricular dysplasia has only been reported in a limited number of cases. ${ }^{45}$ To obtain a clearer picture of the clinical course in these patients we have analysed the clinical characteristics and

Requests for reprints to Dr Carina Blomström-Lundqvist, Division of Cardiology, Medical Department I, Sahlgrenska Hospital, S-413 45 Gothenburg, Sweden.

Accepted for publication 23 June 1987 results of routine diagnostic methods in 15 patients with features consistent with arrhythmogenic right ventricular dysplasia.

\section{Patients and methods}

We studied 15 patients referred for the evaluation of arrhythmias. The clinical features were consistent with previous descriptions of arrhythmogenic right ventricular dysplasia. ${ }^{267}$ The diagnosis of arrhythmogenic right ventricular dysplasia was based upon the electrocardiogram obtained during sinus rhythm and ventricular arrhythmia, the electrophysiological study $(n=11)$, the findings at echocardiography ${ }^{8}(n$ $=15$ ), multigated equilibrium radionuclide angiography with technetium- $99 \mathrm{~m}^{9}(\mathrm{n}=12)$, and cardioangiography $(n=11)$, the histological examination of myocardial specimens obtained at operation or necropsy $(n=6)$, and non-invasive analysis using signal-averaged QRS signals $(n=13)$. Two patients died a few months before admission and their case records were supplied by medical centres nearby 
Table 1 Clinical data on admission and clinical course

\begin{tabular}{|c|c|c|c|c|c|c|}
\hline Case & Age/sex & History duration & Features on admission & $\begin{array}{l}\text { Physical } \\
\text { findings }\end{array}$ & $\begin{array}{l}\text { Clinical course, } \\
\text { arrhythmias (No of } A A \text { drugs) }\end{array}$ & $R H F$ \\
\hline $1 *$ & $23 / \mathrm{F}$ & As admission (2 mnth) & $\begin{array}{l}\text { Fatigue, fever, GI symptoms, } \\
\text { appendicitis? (VT) }\end{array}$ & $\mathbf{N}$ & $\begin{array}{l}\text { Palpitation, recurrent VT first } \\
\text { decade. AF in last } 2 \operatorname{yr}(5)\end{array}$ & $\begin{array}{l}\text { Yes, } 12 \text { yr aft } \\
\text { admission }\end{array}$ \\
\hline 2 & $13 / M$ & Palpitation (1 yr) & Abdominal pain, cough (VT) & $\mathbf{N}$ & $\begin{array}{l}\text { Palpitation, few VT. Remission and } \\
\text { relapse. No VT last } 9 \text { yr (5) }\end{array}$ & 0 \\
\hline 3 & $7 / M$ & 0 & $\begin{array}{l}\text { Fatigue, fever, cough, sinusitis, } \\
\text { GI symptoms (VT) }\end{array}$ & $\begin{array}{l}\text { Split } 2 \text { HS, } \\
\text { SM }\end{array}$ & $\begin{array}{l}\text { Palpitation, faintness. Recurrent VT } \\
\text { with years of remission (2) }\end{array}$ & 0 \\
\hline $4 \dagger$ & $34 / M$ & As admission (1 yr) & $\begin{array}{l}\text { Attacks palpitation faintness, } \\
\text { dyspnoea (VT) }\end{array}$ & $\begin{array}{l}\text { Split } 2 \text { HS } \\
\text { 3rd HS, } \\
\text { SM }\end{array}$ & $\begin{array}{l}\text { Palpitation, faintness. Few VT first } \\
2 \text { yr remission (1) }\end{array}$ & 0 \\
\hline $5 \ddagger$ & $15 / M$ & $\begin{array}{l}\text { Fatigue, fever, } \\
\text { syncope, muscle pain, } \\
\text { sore throat ( } 3 \mathrm{mnth})\end{array}$ & $\begin{array}{l}\text { Fatigue, faintness, tonsillitis. } \\
\text { Ventricular extrasystoles }\end{array}$ & $\begin{array}{l}\text { 3rd HS, } \\
\text { SM PL }\end{array}$ & $\begin{array}{l}\text { Fatigue, faintness for a few mnth. } \\
\text { Palpitation. Ventricular extrasystoles } \\
\text { (0) }\end{array}$ & 0 \\
\hline $6 \ddagger$ & $13 / \mathrm{F}$ & $\begin{array}{l}\text { Upper respiratory tract } \\
\text { illness (1 wk); faintness } \\
(1 \mathrm{yr})\end{array}$ & $\begin{array}{l}\text { Faintness, fatigue, chest pain } \\
\text { (VT) }\end{array}$ & $\begin{array}{l}\text { Split 2 HS } \\
\text { 3rd HS, } \\
\text { PL }\end{array}$ & $\begin{array}{l}\text { Fatigue for a few mnth. No relapse } \\
\text { VT. Ventricular extrasystoles (1) }\end{array}$ & 0 \\
\hline $7 \S$ & $41 / M$ & 0 & Palpitation (VT) & 3rd HS & $\begin{array}{l}\text { Palpitation. Recurrent VT. } \\
\text { Operation after } 3 \text { mnth (2) }\end{array}$ & 0 \\
\hline $8 \S$ & $15 / M$ & As admission (1 yr) & Palpitation on exertion (VT) & 3rd HS, PL & $\begin{array}{l}\text { Palpitation. Few VT in first years, } \\
\text { monthly relapses (6) }\end{array}$ & 0 \\
\hline 9 & $40 / F$ & $\begin{array}{l}\text { Attacks faintness, and } \\
\text { dyspnoea (1 yr) }\end{array}$ & $\begin{array}{l}\text { Attacks palpitation, faintness, } \\
\text { dyspnoea (VT) }\end{array}$ & $\mathbf{N}$ & $\begin{array}{l}\text { Palpitation, syncope. Recurrent VT. } \\
\text { Operation after } 3 \text { yr (5) }\end{array}$ & 0 \\
\hline 10 & $29 / M$ & Palpitation (4 mnth) & $\begin{array}{l}\text { Attacks palpitation, chest } \\
\text { oppression (VT) }\end{array}$ & $\begin{array}{l}\text { Split } 2 \text { HS } \\
\text { 3rd, 4th } \\
\text { HS }\end{array}$ & $\begin{array}{l}\text { Palpitation. Few VT in first yr } \\
\text { frequent relapses after } 7 \mathrm{yr}(4)\end{array}$ & 0 \\
\hline 11 & $24 / M$ & $\begin{array}{l}\text { Attacks dyspnoea on } \\
\text { exertion ( } 3 \text { mnth) }\end{array}$ & Cardiac arrest (VF) & $\mathbf{N}$ & $\begin{array}{l}\text { Resistant VT/VF in first yr despite } \\
\text { surgery } \rightarrow \text { remission } \rightarrow \text { late relapse }(8)\end{array}$ & $\begin{array}{l}\text { Yes } \\
\text { postopera- } \\
\text { atively. } \\
\text { Tricuspid } \\
\text { valve surger }\end{array}$ \\
\hline 12 & $50 / \mathrm{M}$ & 0 & $\begin{array}{l}\text { Faintness, several episodes of } \\
\text { syncope, nausea (AFl) }\end{array}$ & $\mathbf{N}$ & $\begin{array}{l}\text { Afl and SVT in first years. Single VT, } \\
\text { no relapse }(0)\end{array}$ & $\begin{array}{l}\text { Yes, } 1 \text { yr afte } \\
\text { admission }\end{array}$ \\
\hline 13 & $42 / F$ & $\begin{array}{l}\text { Attacks of palpitation } \\
\text { and dyspnoea. } \\
\text { Ventricular } \\
\text { extrasystoles (18 yr) }\end{array}$ & $\begin{array}{l}\text { Palpitation, several episodes of } \\
\text { syncope (VT) }\end{array}$ & $\mathbf{N}$ & $\begin{array}{l}\text { Palpitation, faintness, VT } \\
\text { becoming progressively worse. } \\
\text { Surgery after } 9 \text { yr (11) }\end{array}$ & 0 \\
\hline 14 & $49 / F$ & As admission $(5 \mathrm{yr})$ & $\begin{array}{l}\text { Attacks of palpitation faintness, } \\
\text { fatigue (VT) }\end{array}$ & $\mathbf{N}(\mathbf{H T})$ & $\begin{array}{l}\text { Palpitation, no faintness. No VT. } \\
\text { Ventricular extrasystoles (1) }\end{array}$ & 0 \\
\hline 15 & $41 / M$ & $\begin{array}{l}\text { Chest oppression on } \\
\text { exertion }(5 \mathrm{yr})\end{array}$ & $\begin{array}{l}\text { Syncope, palpitation on exertion } \\
\text { (VT } \rightarrow \text { AVNRT) }\end{array}$ & $\mathbf{N}$ & $\begin{array}{l}\text { Faintness and palpitation on } \\
\text { exertion. No syncope (7) }\end{array}$ & 0 \\
\hline
\end{tabular}

^Friedrich's ataxia in three sisters; †spleenectomy for congenital haemolytic anaemia; łbrother and sister; §father and son.

0 , none; GI, gastrointestinal; VT, ventricular tachycardia; VF, ventricular fibrillation; AVNRT, atrioventricular nodal reentrant tachycardia; AF, atrial fibrillation, AFl, atrial flutter; SVT, supraventricular tachycardia; N, normal; HS, heart sound; SM, systolic murmur; PL, precordial lift; HT, hypertension; AA, oral antiarrhythmic agents for ventricular arrhythmias; RHF, right heart failure.

Table 2 Characteristics of ventricular arrhythmia

\begin{tabular}{|c|c|c|c|c|c|}
\hline \multirow[b]{2}{*}{ Case } & \multirow{2}{*}{$\begin{array}{l}\text { Ventricular } \\
\text { extrasystole type }\end{array}$} & \multirow[b]{2}{*}{ Rate (beats/min) } & \multirow[b]{2}{*}{ Configuration (No) } & \multicolumn{2}{|l|}{ Ventricular tachycardia } \\
\hline & & & & Vector & Attacks \\
\hline $\begin{array}{r}1 \\
2 \\
3 \\
4 \\
5 \\
6 \\
7 \\
8 \\
9 \\
10 \\
11 \\
12 \\
13 \\
14 \\
15\end{array}$ & 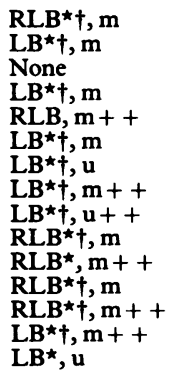 & $\begin{array}{l}120-200 \\
200-260 \\
150-250 \\
150-240 \\
- \\
250 \\
200-240 \\
120-190 \\
170-260 \\
150-250 \\
130-250 \\
165 \\
200-250 \\
200-250 \\
270\end{array}$ & $\begin{array}{l}\text { LBBB (3) } \\
\text { LBBB (2) } \\
\text { LBBB (2) } \\
\text { LBBB (1) } \\
- \\
\text { LBBB (1) } \\
\text { LBBB (1) } \\
\text { LBBB (3) } \\
\text { LBBB (1) } \\
\text { LBBB (2) } \\
\text { LBBB (2) } \\
\text { LBBB (1) } \\
\text { LBBB (1) } \\
\text { LBBB (1) } \\
\text { LBBB (1) }\end{array}$ & $\begin{array}{l}-15,-45,-60,+75,+60 \\
-60,+90 \leftrightarrow+105 \\
+-0,(-15 ?)+75,(-90 ?) \\
-60 \\
- \\
+75 \\
-45 \\
+105, \leftrightarrow-30,-45 \\
+105 \\
-60,+75 \\
+105,-60 \\
-75 \\
+105 \\
+90 \\
?\end{array}$ & $\begin{aligned} &> 10 \\
&> 10 \\
& 6-10 \\
& 2-5 \\
&- \\
& 1 \\
& 2-5 \\
& 6-10 \\
&> 10 \\
&> 10 \\
&> 10 \\
& 1 \\
&> 10 \\
&> 10 \\
& 2-5\end{aligned}$ \\
\hline
\end{tabular}

m, multifocal; $u$, unifocal; *ventricular extrasystoles of identical QRS configuration as VT; tventricular extrasystoles of QRS configuration othe? than VT; RLB, right and left bundle branch block configuration; ++ , frequently recorded on electrocardiogram often in couplets, bigeminy, of trigeminy;NS, non-sustained; EVT, VT induced at or after ergometer stress test; ND, not done; DC, direct current countershock; AA, antiarrhythmic agent administered intravenously; RV, right ventricular (OT, outflow tract; $A$, anterior wall); tri, tricuspid region; $\leftrightarrow$, alternating during the same attack.

See footnote to table 1 for other abbreviations. 
(cases 5 and 12). Three patients have been described in earlier reports (cases 7, 8, and 11). ${ }^{1011}$. The clinical history, physical examination, resting 12 lead electrocardiogram, and chest $x$ ray $^{12}$ at first admission, during follow up, and at the end of follow up were evaluated in each patient: The QRS configuration during spontaneous ventricular tachycardia was classified according to the bundle branch block pattern in the precordial leads. Ventricular tachycardia was defined as sustained ( $\geqslant 30 \mathrm{~s})$ or nonsustained $(<30 \mathrm{~s})$. An episode of ventricular tachycardia was defined as either an isolated sustained tachycardia or as incessant short runs of tachycardias.

\section{Results}

\section{CLINICAL CHARACTERISTICS (TABLE 1)}

The mean age at onset of symptoms was 27 years (range 7-50 years). The ratio of males to females was 2:1. Eleven patients had a previous history of arrhythmia-related symptoms, defined as palpitation, faintness, syncope, and attacks of dyspnoea or chest oppression, alone or in combination. Three patients had no previous history before they presented with tachycardia. The mean time from onset of symptoms to admission to hospital was 2.3 years (range 0-18 years). Nine patients had a history of symptoms of one year or less and three patients a history of 5-18 years.

The patients' mean age at first hospital admission was 29 years (range 7-50 years). Twelve patients presented with ventricular tachycardia, one with ventricular fibrillation, one with ventricular extra- systoles, and another patient with atrial flutter. In six patients ventricular tachycardia emerged during an infection (cases $1,2,3,5,6$, and 12). In these patients the clinical picture, and routine blood tests or electrocardiogram or both indicated acute myocardial damage.

\section{Characteristics of arrhythmia (table 2)}

Ventricular tachycardia occurred in all but one patient who had only ventricular extrasystoles. The ventricular tachycardias were sustained in 12 patients, 10 of whom usually required intervention with antiarrhythmic drugs or DC countershock or both for conversion to sinus rhythm, and two of whom usually had self-terminating tachycardia (cases 4 and 13). Two patients had non-sustained ventricular tachycardia, which in one of them developed into atrioventricular nodal reentrant tachycardia. Three patients suffered mainly from bouts of uniform incessant tachycardia (cases 9, 13, and 14). Ventricular fibrillation occurred during a preoperative electrophysiological test in two patients (cases 7 and 11) and case 11 also had two episodes out of hospital. Seven patients reported effort-related palpitation or tachycardia and in six of them ventricular tachycardia was induced during ergometer stress testing or in the immediate postexercise period. Syncope was experienced by five patients, three of whom underwent 24 hour Holter: monitoring, which confirmed a relation with tachycardia (cases 9, 13, and 1.5).

Severe hypotension or circulatory shock occurred during some episodes of tachycardia in six patients (cases $1,3,6,9,10$, and 11) while in three patients

\begin{tabular}{llll}
\hline Type & Effort related palpitation/EVT & Treatment DC/AA/other & Electrophysiological study/VT origin \\
\hline Sustained & Yes/yes & DC, AA, Stellatum blockade & Yes/? \\
Sustained & Yes/yes, VE $\downarrow$ & DC, AA, stellatum blockade & Yes/? \\
Sustained (5 day) & No/no, & DC, AA & ND \\
Sustained & No/no, VE $\downarrow$ & 0 & ND \\
- & No/no,VE $\downarrow$ & DC & YD \\
Sustained & No/ND & DC, AA & RVA (tri) \\
Sustained & No/ND & DC, AA & RVOT, RVA, tri \\
Sustained & Yes/no & AA & RVOT \\
Sustained (min) & No/no, VE $\downarrow$ & DC, AA & Tri, RVOT \\
Sustained & No/no & DC, AA & RVOT \\
Sustained & Yes/yes & DC, AA & ND \\
Sustained & No/ND & AA & RVOT \\
Sustained (min) & Yes/yes, VE $\downarrow$ & AA & RVOT \\
NS (10 beats) & Yes/yes, VE $\uparrow$ & O & Yes/? VT $\rightarrow$ AVNRT \\
NS (3-10 beats) & Yes/yes, VE $\uparrow$ & & \\
\hline
\end{tabular}




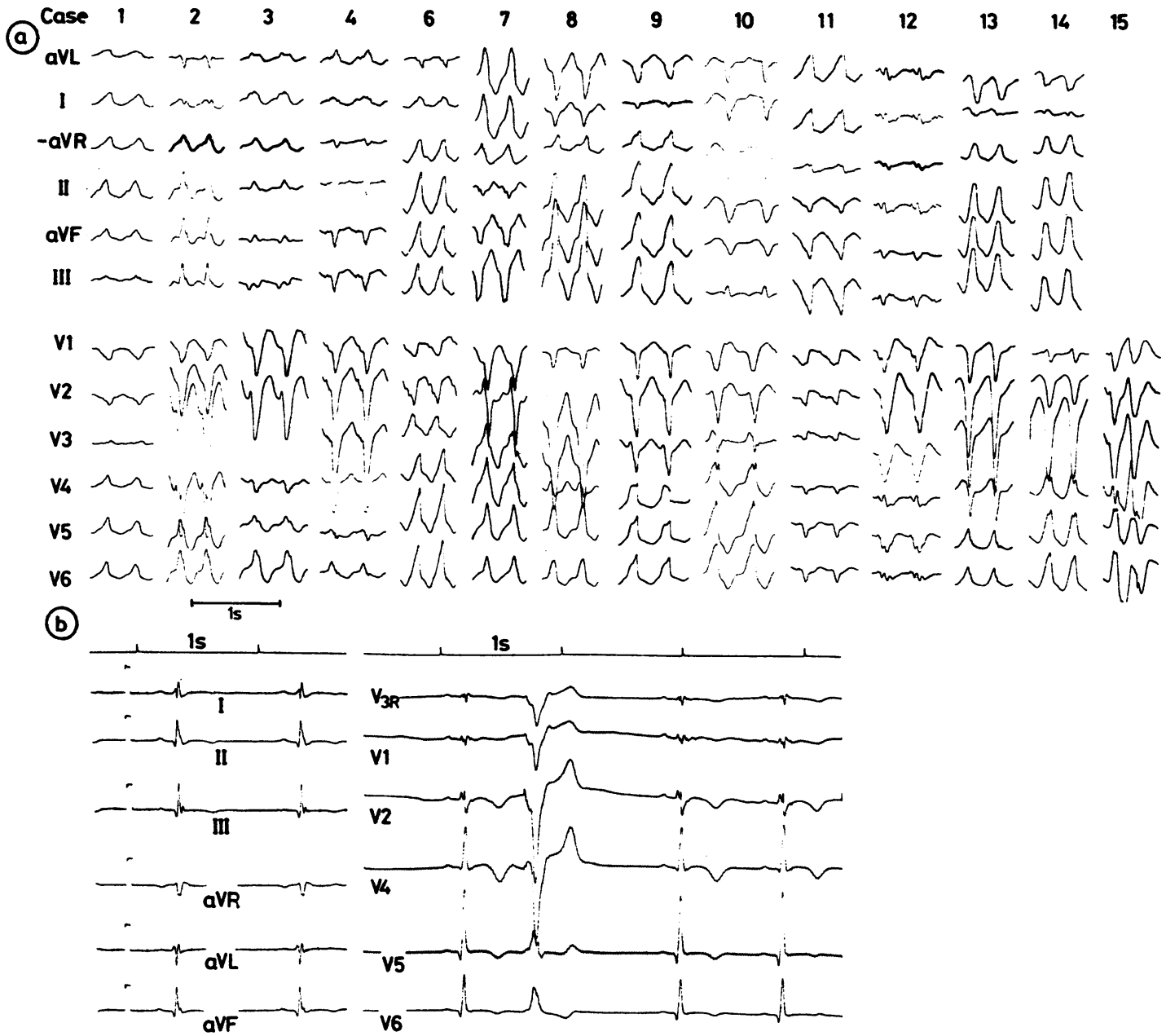

Fig 1 (a) Electrocardiograms obtained during ventricular tachycardia from each of the 14 patients and (b) during sinus rhythm with ventricular extrasystoles in case 5. The QRS configuration was of atypical left bundle branch block pattern in cases 11 and 12. Paper speed $50 \mathrm{~mm} / \mathrm{s}$.

haemodynamic function was not affected (cases 4, 8 , and 12). The electrocardiogram during ventricular tachycardia showed a left bundle branch block pattern and in each case the initiating QRS complex and subsequent complexes had the same configuration (table 2, fig 1). The frontal plane axes ranged from -75 to +105 degrees, whereas axes between -30 and +60 degrees were uncommon. Six patients had two or more clinical types of ventricular tachycardia that were uniform during the same attack but showed different patterns from one attack to another. In two of these patients, however, two types of ventricular tachycardia appeared dur- ing the same attack (cases 2 and 8 ). In each case the left bundle branch block pattern was retained. The ventricular rate ranged from 120 to 270 beats/minutes. Thirteen out of 14 patients with ventricular tachycardia had ventricular extrasystoles on the resting 12 lead electrocardiogram. The QRS configuration was identical with that during ventricular tachycardia in each case. Multifocal ventricular extrasystoles were seen in 11 patients. Ventricular extrasystoles with a right bundle branch block pattern were less common; they appeared in six patients. Six patients had frequent ventricular extrasystoles which often appeared as bigeminy, trigem- 
Table 3 Details of follow up

\begin{tabular}{|c|c|c|c|c|c|c|}
\hline Case & $\begin{array}{l}\text { Duration of } \\
\text { follow up (yr) }\end{array}$ & Symptoms & Arrhythmias & Physical findings & $\begin{array}{l}\text { Subsequent } \\
\text { AA treatment }\end{array}$ & $\begin{array}{l}\text { Functional } \\
\text { classes during } \\
\text { follow up }\end{array}$ \\
\hline 1 & 24 & Fatigue & Chronic AF and VPC & $\begin{array}{l}\text { RHF, faint HS, 3rd HS, } \\
S M, P L\end{array}$ & Digitalis, verapamil (AF) & $I \rightarrow$ III \\
\hline 2 & 22 & Palpitation & Ventricular extrasystoles & $\underset{\text { PL }}{\text { Split } 2 ~ H S, ~ 3 r d ~ H S, ~ S M, ~}$ & Mexiletine & I \\
\hline 3 & 28 & Palpitation & VT, ventricular extrasystoles & $\underset{\text { SM }}{\text { CVP }}$, split 2 HS, 4th HS, & Quinidine & I \\
\hline $\begin{array}{l}4 \\
5 \\
6 \\
7 \\
8\end{array}$ & $\begin{array}{l}7 \\
1 \cdot 5^{\star} \\
6 \\
2 \cdot 5(2 \cdot 5) \\
3\end{array}$ & $\begin{array}{l}\text { Palpitation } \\
\text { Asymptomatic } \\
\text { Asymptomatic } \\
\text { 0 after operation } \\
\text { Palpitation }\end{array}$ & $\begin{array}{l}\text { Ventricular extrasystoles } \\
\text { Ventricular extrasystoles }++ \\
\text { Ventricular extrasystoles } \\
\text { Ventricular extrasystoles } \\
\text { Ventricular extrasystoles }++\end{array}$ & $\begin{array}{l}\text { CVP†, split } 1 \text { and } 2 \text { HS } \\
\text { 3rd HS, SM, PL } \\
\text { Split 2 HS } \\
\text { 3rd HS, SM } \\
\text { 3rd HS, SM }\end{array}$ & $\begin{array}{l}\text { Disopyramide } \\
0 \\
\text { Pindolol } \\
0 \text { after operation } \\
\text { Amiodarone and } \\
\text { mexiletine }\end{array}$ & $\begin{array}{l}\operatorname{III}_{\text {II } \rightarrow I} \\
\text { I } \\
\text { I }\end{array}$ \\
\hline $\begin{array}{r}9 \\
10 \\
11\end{array}$ & $\begin{array}{l}5 \cdot 5(2) \\
9 \\
6(5 \cdot 5)^{\star}\end{array}$ & $\begin{array}{l}0 \text { after operation } \\
\text { Palpitation } \\
\text { Fatigue, chest } \\
\text { oppression }\end{array}$ & $\begin{array}{l}\text { Ventricular extrasystoles } \\
\text { Ventricular extrasystoles } \\
\text { Episode of VT/VF a few wk before } \\
\text { death. Ventricular extrasystoles }\end{array}$ & $\begin{array}{l}\text { N } \\
\text { Split 2 HS, 4th HS } \\
\text { RHF, 3rd HS, SM, DM }\end{array}$ & $\begin{array}{l}0 \text { after operation } \\
\text { Flecainide and sotalol } \\
\text { Quinidine, pindolol }\end{array}$ & $\underset{\text { I }}{\mathbf{I}} \rightarrow$ III \\
\hline 12 & $4 \dagger$ & $\begin{array}{l}\text { Fatigue, } \\
\text { dyspnoea }\end{array}$ & AV block I, ventricular extrasystoles & $\begin{array}{l}\text { RHF, faint HS, split } 2 \text { HS, } \\
\text { 3rd HS }\end{array}$ & digitalis, verapamil (SVT) & $I \rightarrow$ III \\
\hline $\begin{array}{l}13 \\
14 \\
15\end{array}$ & $\begin{array}{l}9(0 \cdot 1) \\
3 \\
2\end{array}$ & $\begin{array}{l}0 \text { after operation } \\
\text { Palpitation } \\
\text { Asymptomatic }\end{array}$ & $\begin{array}{l}\text { Ventricular extrasystoles }++ \\
\text { Ventricular extrasystoles }++ \\
0\end{array}$ & $\begin{array}{l}\mathbf{N} \\
\mathbf{N} \\
\mathbf{N}\end{array}$ & $\begin{array}{l}0 \text { after operation } \\
\text { Sotalol } \\
\text { Amiodarone }\end{array}$ & $\underset{I}{I}$ \\
\hline
\end{tabular}

Symptoms and arrhythmias include those present during the past six months. Clinical data of patients who died are those that were present at the last examination before death. The figures in brackets under follow up show the follow up period after operation for arrhythmia.

*Sudden death; †died in circulatory shock; + + ventricular extrasystoles frequently recorded on electrocardiogram and often in pairs, bigeminy, or trigeminy; CVP, central venous pressure. See table 1 for other abbreviations.

iny, or pairs, and in four of these patients the QRS configuration was identical with that during ventricular tachycardia (cases $8,9,13$, and 14).

\section{TREATMENT}

Antiarrhythmic agents were prescribed for 13 patients to prevent ventricular tachycardia. These were used alone or in combination and included various $\beta$ blockers in nine patients, disopyramide in seven, sotalol in five, mexiletine in five, quinidine in five, procainamide in three, tocainide in three, flecainide in four, amiodarone in two, and phenobarbitone, phenytoin, ajmalin, and carbamazepine in one patient each (table 1). These agents proved to be ineffective and table 3 shows the subsequent antiarrhythmic treatment. Three patients remained on the single drug initially administereddisopyramide, pindolol, and sotalol (cases 4,6, and 14). Several antiarrhythmic drugs were tested in the remaining 10 patients. Flecainide was arrhythmogenic in one case. The efficacy of the drugs was difficult to evaluate because of the variable course of the arrhythmias (fig 2). Two patients (cases 3 and 10) have had long tachycardia-free intervals on the current antiarrhythmic treatment. One patient (case 1) has had no relapse of ventricular tachycardia for two years, despite the withdrawal of antiarrhythmic treatment (case 1). Antiarrhythmic drugs were used to treat supraventricular tachycardia or atrial fibrillation in three patients (cases 1, 12, and 15) and diuretics for right heart failure in three patients (cases 1, 11, and 12).

Four patients eventually required an operation to treat arrhythmia. Patient 7 had an operation a few months after admission. ${ }^{10}$ and patients 9 and 13 had one, three and nine years respectively after admission. In both the origin of the ventricular tachycardia was in the right ventricular outflow tract. A transmural incision and cryoablation were performed. The hearts appeared macroscopically normal but biopsy specimens from the site of origin of the arrhythmia showed large fat vacuoles in the myofibres. Patient 11 had two operations for arrhythmia within a year of admission. ${ }^{11}$

\section{CLINICAL COURSE (TABLE 3 and FIG 2)}

The follow up period (from first being seen by a cardiologist) ranged from 1.5 to 28 years (mean 8.8 years).

\section{Arrhythmias}

The number of episodes of ventricular tachycardia that required hospital admission varied widely (fig 2). The following groups were identified: (a) recurrent attacks of intractable sustained ventricular tachycardia requiring hospital admission for several days or months, interspersed with remissions for up to several years in three patients followed for a mean of 17 years (range 6-24 years) (cases 1, 2, and 11).

Patient 1 had recurrent ventricular tachycardia for 


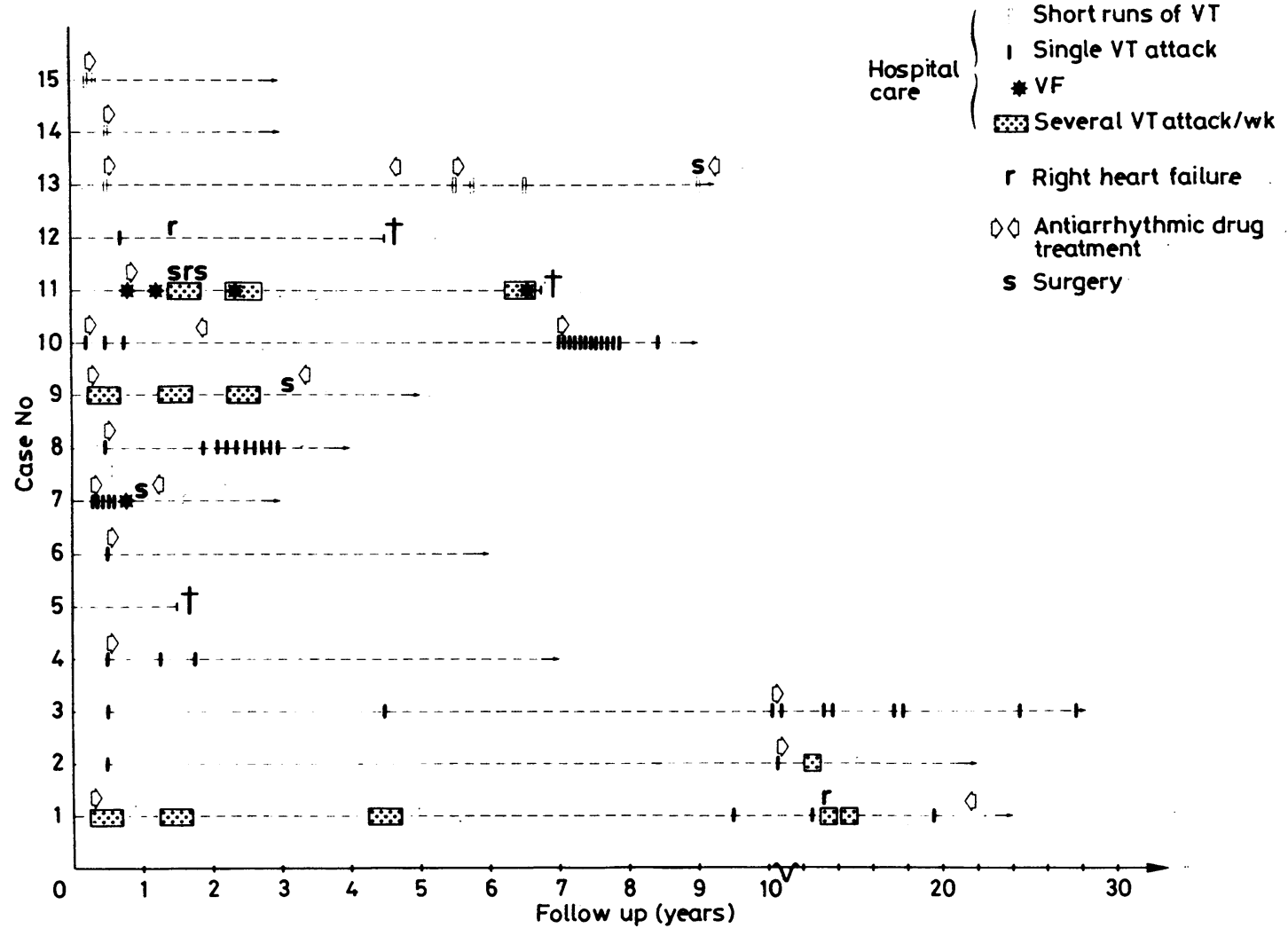

Fig 2 The course of the ventricular arrhythmias from first admission (time zero) to the last follow up. Only episodes of ventricular tachycardia that required hospital admission are shown. The open arrows indicate the start and end of treatment with antiarrhythmic drug(s) for ventricular tachycardia. Changes of drugs are not shown. †death; $V T$, ventricular tachycardia; $V F$, ventricular fibrillation.

over 10 years followed by chronic atrial fibrillation. Drugs given to treat ventricular tachycardia were then withdrawn without causing relapse. Patient 2 has had no trial of drug withdrawal. In patient 11 a second type of ventricular tachycardia appeared a year after the last operation. Partial suppression was achieved with antiarrhythmic drugs and the patient gradually recovered. The patient died suddenly out of hospital five years after the operation for arrhythmia. A few weeks earlier he had relapsed with ventricular tachycardia, ventricular fibrillation, and right heart failure.

(b) Recurrent isolated attacks of sustained ventricular tachycardia with up to several years of remissions occurred in five patients followed for 2.5-28 years (mean 10 years) (cases 3, 4, 7, 8, 10). Patient 3 has had well tolerated attacks of ventricular tachycardia while on the same drug regimen for the past three years. Patient 4 has had no relapse in the past five years. Patient 7 is free from ventricular tachycardia 2.5 years after operation for arrhythmia. Ventricular extrasystoles with a QRS configuration identical with that during previous ventricular tachycardia have been documented. Patient 8 , who initially had ventricular tachycardias only on exertion, deteriorated, experiencing frequent attacks at rest and two additional types of ventricular tachycardia. On amiodarone and mexiletine no relapse has occurred in the past six months. Patient 10, who relapsed after several years of remission, refused operation for arrhythmia and has been on flecainide and sotalol for the past 1.5 years. This has led to a gradual suppression of the tachycardias.

(c) Episodes with repetitive short runs of usually self terminating ventricular tachycardia occurred in three patients followed for 3-9 years (mean six years) (cases 9, 13, and 14). Two patients have had no recurrence of ventricular tachycardia 0.5 and two 
years after operation for arrhythmia. Ventricular extrasystoles with a QRS configuration identical with that seen during previous ventricular tachycardia have been noted. One patient has had no relapse on sotalol in the past two years.

(d) Two patients followed for 4-6 years had single attacks of sustained ventricular tachycardia. Patient 6 has had no trial of drug withdrawal. The patient's brother had a less favourable course (case 5). Supraventricular tachycardias in patient 12 were treated medically for a year. The patient died four years after admission of circulatory shock after severe right heart failure was followed by cardiac arrest. Necropsy showed right ventricular dilatation with fat infiltration and fibrosis, and multiple fresh pulmonary emboli. There was a mild left ventricular dilatation.

(e) Frequent ventricular extrasystoles with a left bundle branch block pattern but no ventricular tachycardia occurred in one patient (case 5). No treatment was started. The patient died suddenly out of hospital during exercise. Necropsy showed right ventricular dilatation with abundant adipose and fibrous tissue.

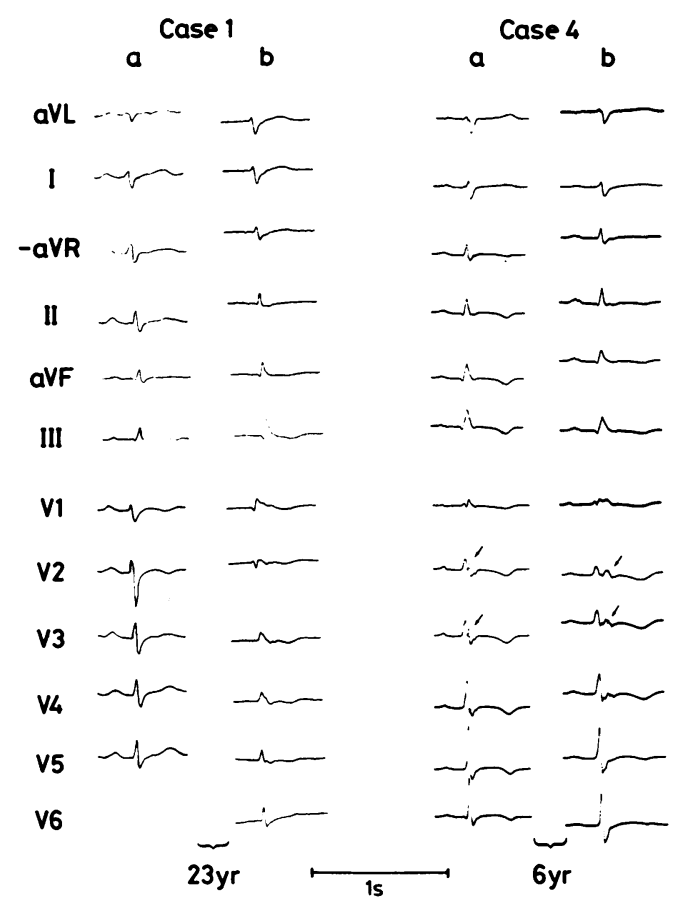

(f) Short non-sustained ventricular tachycardia developed in atrioventricular nodal reentrant tachycardia in one patient (case 15). There has been no arrhythmia in the past year on amiodarone.

\section{Right heart failure}

Three patients developed a severe right heart failure (cases 1,11 , and 12). In patient 1 progressive right heart failure developed insidiously after approximately 10 years. In patient 11 tricuspid incompetence developed after operation for arrhythmia and reconstruction of the tricuspid valve was required. Signs of a progressive right heart failure have developed slowly during the past few years. In patient $\mathbf{1 2}$ right heart failure developed insidiously approximately one year after admission.

The ventricular tachycardia apparently became less frequent as the right heart function deteriorated. No patient developed left heart failure.

\section{Physical findings}

At admission seven patients had abnormal physical findings (table 1). No patient had asymmetry of the precordium or clinical signs of overt right or left

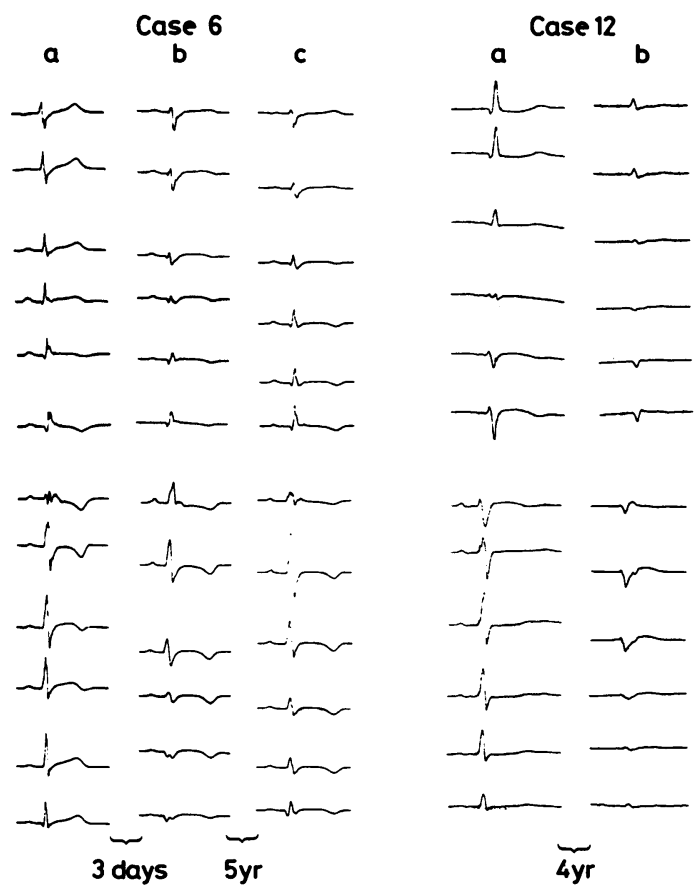

Fig 3 Resting electrocardiogram during sinus rhythm on first admission (a) and at last follow up (b). Case 1: note the development of low voltage, inverted $T$ waves and delayed potentials. Case 4: note the intraventricular conduction disturbance (arrow) in (a), followed by pronounced delayed potentials (arrow) in (b). Case 6: note the $S T$ elevations followed by $Q$ waves and inverted $T$ waves indicating acute myocardial damage. Delayed potentials were present from first admission. Case 12: note the development of low voltage and delayed potentials. Paper speed $50 \mathrm{~mm} / \mathrm{s}$. 


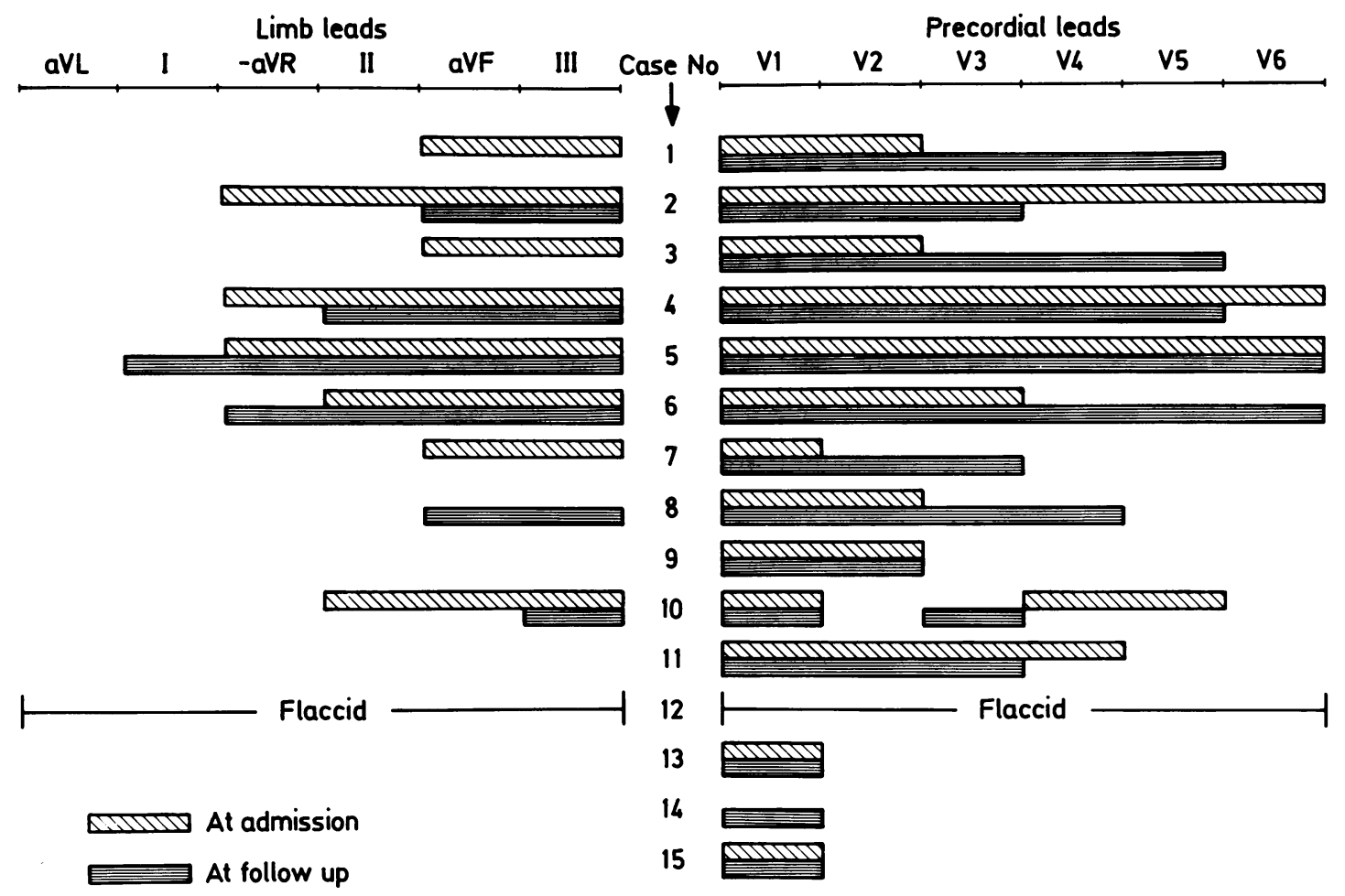

Fig 4 Extension of repolarisation changes on first admission compared with last follow up. Note the regression of $T$ wave inversions in some patients; in most these were followed by the development of $Q$ waves in corresponding leads. The illustrated $T$ wave inversions in case 3 on admission were recorded four years after admission because at that time the precordial leads were incomplete.

heart failure. Four patients developed abnormal physical findings including a split first heart sound in one patient, a wide split second heart sound in two, a third heart sound in one, and a fourth heart sound in one patient (table 3). Systolic murmurs, graded $0.5-\mathrm{II} / \mathrm{IV}$ over the lower left sternum, evolved in four patients. Doppler echocardiography confirmed pulmonary insufficiency in one patient (case 11).

While they were in sinus rhythm, three patients in functional class I ended up in class III after right heart failure and two in class II and one patient in class III ended up in class I. The remaining patients remained in class I of the New York Heart Association classification.

Electrocardiogram during sinus rhythm (figs 3 and 4) Of the 15 patients, who had sinus rhythm at admission, one patient developed chronic atrial fibrillation and one patient an atrial ectopic rhythm. First degree atrioventricular block developed in one patient and intermittent intra-atrial block in another.

The mean (SD) QRS interval was significantly prolonged $(0.10(0.01) \mathrm{s}$ (range $0.08-0.13 \mathrm{~s})$ versus $0.11(0.02) \mathrm{s}$ (range 0.10 to $0.15 \mathrm{~s}$ ), $\mathrm{p}<0.05$ ). Two patients developed an incomplete and four a complete right bundle branch block. In most cases ventricular post-excitation waves, mainly confined to the right precordial leads, accounted for the prolonged QRS intervals. Delayed potentials, suspected in six patients at admission, developed in six other patients, and previously noted deflections appeared to become more pronounced. Two out of six patients with a previously normal electrocardiogram developed right precordial $\mathrm{T}$ wave inversions. Left precordial $T$ wave inversions evolved in three patients, two of whom also developed left precordial Q waves. Figure 4 shows a schema of the $T$ wave changes. Three patients developed $Q$ waves which were confined to left precordial or inferior leads. Most of the ST changes that had been seen before were less 
Table 4 Chest radiography on admission and at last follow up

\begin{tabular}{|c|c|c|c|c|}
\hline \multirow[b]{2}{*}{ Case No } & \multicolumn{3}{|c|}{ Cardiac size } & \multirow[b]{2}{*}{ Interval (years) * } \\
\hline & Admission & Follow up & Change & \\
\hline 1 & $\mathbf{R V}+$ & $\mathrm{RV} \uparrow 1210$ & $\uparrow$ & 24 \\
\hline 2 & $\operatorname{Biv} \uparrow 470$ & Biv $\uparrow 550$ & $\uparrow$ & 22 \\
\hline 3 & Normal & $\mathrm{RV} \uparrow 800$ & & 28 \\
\hline 4 & $\mathrm{RV} \uparrow 550$ & $\mathbf{R V} \uparrow 520$ & None & 7 \\
\hline 5 & Biv $\{680$ & Biv $\uparrow 500$ & & 1.5 \\
\hline 6 & $\mathrm{BIV} \uparrow 510$ & $\operatorname{Biv} \uparrow 540$ & None & 6 \\
\hline 7 & & $\mathbf{N}$ & None & $2 \cdot 5$ \\
\hline 8 & $\mathbf{N}$ & $\mathbf{N}$ & None & 3 \\
\hline 9 & $\mathbf{N}$ & $\mathbf{N}$ & None & $5 \cdot 5$ \\
\hline 10 & $\mathbf{N}$ & $\mathbf{N}$ & None & 9 \\
\hline 11 & $\mathbf{N}$ & $\mathrm{RV} \uparrow 760$ & & 6 \\
\hline 12 & Biv $\uparrow 660$ & & $\uparrow$ & 4 \\
\hline 13 & & & None & 9 \\
\hline 14 & $\mathbf{R V}+$ & Biv $\uparrow 530$ & & 3 \\
\hline 15 & & $\mathbf{N}$ & None & 2 \\
\hline
\end{tabular}

Cardiac size is given as the relative heart volume-volume: body surface area $\left(\mathrm{ml} / \mathrm{m}^{2}\right) .{ }^{12} \mathrm{RV}+$, prominent right ventricle; biv, biventricular.

$\star$ Years between the first and last chest $x$ ray.

pronounced. One patient developed a right frontal plane axis. Low voltage electrocardiogram (defined as QRS amplitudes $<5 \mathrm{~mm}$ in leads I, II, and III, or $<10 \mathrm{~mm}$ in all precordial leads) evolved in two patients.

\section{Chest radiography (table 4)}

The size of the heart increased in four out of 10 patients with previously normal relative heart volumes and in two out of five patients with previously enlarged hearts. The increasing heart sizes did not seem to parallel the course of the ventricular arrhythmias. The largest hearts were found in patients with right heart failure. No patient had pulmonary congestion.

\section{Discussion}

Although several reports have characterised arrhythmogenic right ventricular dysplasia, little attention has been paid to changes that may appear with time in physical examination, electrocardiography, or chest $x$ ray. Furthermore, the paucity of long term follow up studies has precluded a statement on the clinical course. The present study, however, enabled us to establish a composite clinical profile and to elucidate further the clinical outcome in this group of patients. We attempted to reconcile our data with other published reports on arrhythmogenic right ventricular dysplasia.

\section{CLINICAL CHARACTERISTICS}

The main clinical signs of recurrent sustained right ventricular tachycardia and the frequency and severity of arrhythmias accorded with the other reports. ${ }^{21314}$ We found that ventricular arrhythmias may not become apparent until continuous telemetry is performed (cases 1 and 5).

Spontaneous episodes of ventricular tachycardia showing different frontal QRS axes were more common in our patient than in a larger study, ${ }^{2}$ but resembled findings in other reports. ${ }^{7}$ Different $Q R S$ configurations imply different sites of origin in the right ventricle, although, in the absence of operative mapping, the possibility that there were exit points in the same region cannot be entirely excluded. Two $(13 \%)$ of our patients experienced ventricular fibrillation. Their previous histories and clinical features were not distinctly different from those of the other patients. Others have called attention to both clinically occurring and inducible ventricular fibrillation in arrhythmogenic right ventricular dysplasia. ${ }^{71516}$ The significance of the latter remains to be clarified. ${ }^{1718}$ Multiple configurations of ventricular tachycardia and ventricular fibrillation imply electrical instability, which in turn may reflect the widespread nature of the right ventricular disturbance. This was supported by the observation that multiple types of ventricular tachycardia were mainly found in patients with the most pronounced right ventricular wall motion abnormalities. Patients with right ventricular tachycardia and abnormalities of right ventricular structure appear to have a less benign clinical presentation and less favourable findings at electrophysiological study. ${ }^{19}$

The incidence of supraventricular arrhythmias was low and comparable with that reported previously, ${ }^{27}$ as was the incidence of clinical abnormalities of atrioventricular conduction ${ }^{213}$ which may only be revealed by electrophysiological testing. ${ }^{20}$ 
In the present study there were two families with arrhythmogenic right ventricular dysplasia detected. ${ }^{10} \mathrm{~A}$ familial occurrence has been reported $^{21521}$ and a genetic pattern has been suggested. ${ }^{2}$ Familial exposure to a common toxic or infectious agent seems likely because of the progressive course and the apparent development of myocardial damage in some patients. Although the term "dysplasia" implies a congenital disorder, the aetiology of arrhythmogenic right ventricular dysplasia remains obscure.

\section{CLINICAL COURSE AND PROGNOSIS}

The mortality among our patients was $20 \%$, which is higher than previously reported. ${ }^{2}$ Two out of three deaths were sudden. Sudden death occurred in one patient who was not receiving treatment because his ventricular extrasystoles seemed to be benign and in another who experienced repeated ventricular fibrillation. In the latter patient, both operation for arrhythmia and the testing of multiple antiarrhythmic drugs failed to prevent life-threatening arrhythmias. Both patients had severe infiltration of the right ventricle by adipose tissue; however, this was also seen in a patient who had only a single attack of ventricular tachycardia. Severe fat infiltration has also been noted in patients with normal right ventriculograms. ${ }^{22}$ We saw an apparent reduction or resolution of ventricular tachycardia in one patient as the right heart function deteriorated. A relation between fatal arrhythmias and previous arrhythmias or degree of right ventricular abnormality was thus difficult to discern. On the basis of our and previous reports, the tendency for sudden death or ventricular fibrillation seems unpredictable. Those affected had a wide range of right ventricular abnormalities on cineangiography, from normal to severely dilated and hypokinetic right ventricles. ${ }^{131523}$ Because of the evident potential for fatal ventricular arrhythmias in patients with arrhythmogenic right ventricular dysplasia an iniensive diagnostic approach is vital so that the adverse prognostic features in this group may be identified.

The prognosis in idiopathic ventricular tachycardia is widely believed to be favourable. ${ }^{2425} \mathrm{By}$ definition, there is no detectable cardiac abnormality. The tachycardia has been described as being the classic form of incessant runs of ventricular tachycardia, ${ }^{26}$ as paroxysmal uniform sustained ventricular tachycardia, ${ }^{24}$ or as left bundle branch block tachycardia with a vertical axis. ${ }^{27}$ Three of our patients shared these electrocardiographical characteristics. The electrocardiograms were normal and only minor regional or global abnormalities were seen on right ventricular angiography. In two of them preoperative right ventricular biopsy was performed. This showed intracellular fat vacuoles, suggesting a mild form of arrhythmogenic right ventricular dysplasia. Even though no patient developed ventricular fibrillation, two of them required operation for arrhythmia, which implies that it may not be correct to describe this arrhythmia as benign.

A recent study showed that ventricular tachycardias caused by arrhythmogenic right ventricular dysplasia do not differ distinctly from idiopathic ventricular tachycardias in terms of the width and the amplitude of the QRS complexes. ${ }^{24}$ As a left bundle branch block pattern during tachycardia is often seen in both populations the only important difference is the occurrence of different configurations in arrhythmogenic right ventricular dysplasia. As the present study shows, however, different QRS during tachycardia may not appear for several years. Moreover, some cases with apparently idiopathic ventricular tachycardia, later diagnosed as arrhythmogenic right ventricular dysplasia, had localised abnormalities or even normal findings on right ventriculography. ${ }^{24}$ It can be difficult to distinguish these clinical entities.

\section{STRUCTURAL PROGRESSION}

The electrocardiographic changes, physical findings, and increasing heart size during follow up all suggest a progressive right heart disorder, which was confirmed by the right ventricular dilatation and functional deterioration in three patients.

Patients with arrhythmogenic right ventricular dysplasia often have non-specific right-sided abnormalities on the surface electrocardiogram during sinus rhythm. ${ }^{21328}$ The observation that electrocardiographic changes developed during follow up, which supported a progressive right-sided disorder, was, however, a novel finding. These changes included the development of incomplete or complete right bundle branch block, right frontal plane axis, right precordial $\mathrm{T}$ wave inversions, and delayed potentials. Different degrees of delayed right ventricular activation are thought to be caused by partial block without definite alteration of the bundle branches. ${ }^{29}$ Most $\mathrm{T}$ wave changes remained constant for years and their importance was hard to evaluate. Low voltage seemed to reflect the degree of right ventricular dilatation, since it only developed in patients with right heart failure.

Abnormal physical findings were more common in our patients than in a larger study. ${ }^{2}$ The frequently encountered widely split second heart sounds may be caused by delayed contraction of the right ventricle. The presence or development of abnormal physical findings seemed to be related to the extent of right ventricular involvement. 
The findings on chest $x$ ray, which showed everything from a completely normal cardiac silhouette to a definitely enlarged heart, accorded with earlier observations. ${ }^{2}$ The increase in heart size seen in $40 \%$ of the cases demonstrated the progressive nature of arrhythmogenic right ventricular dysplasia. A progressive right ventricular disorder and a left ventricular involvement were confirmed in one patient (case 6) by serial echocardiograms. A progressive course has been reported in isolated cases. ${ }^{430} \mathrm{~A}$ new finding was that several of our patients developed signs of acute myocardial damage, some of which seemed related to a previous infection. The presence of development of a left ventricular involvement was suggested by the $T$ wave inversions and $Q$ waves in the left precordial leads and by the right bundle branch block pattern of the ventricular extrasystoles. It was confirmed at operation or necropsy in three patients. Left ventricular involvement may be more common than shown by cineangiography. ${ }^{31}$ Extensive left ventricular involvement ${ }^{2432}$ and pulmonary congestion are rare. $^{33}$

\section{TREAT MENT}

Most of our patients with arrhythmogenic right ventricular dysplasia were managed medically. The efficacy of various antiarrhythmic agents has not been systematically evaluated. Medical treatment was effective in abolishing ventricular tachycardia in approximately $50 \%$ of patients. ${ }^{2}$ Apparent spontaneous resolution of ventricular arrhythmias was reported in isolated cases. ${ }^{56}$ Operation for arrhythmia seems to be effective in preventing most episodes of recurrent venticular tachycardia, ${ }^{34}{ }^{35}$ although ventricular tachycardia of different configurations has appeared after successful operation. ${ }^{34}$ The apparent instability of the ventricular arrhythmias makes it difficult to be certain when operation is indicated or even when it is effective.

This study was supported by grants from the Swedish National Association Against Heart and Chest Disease and the Medical Society of Gothenburg.

\section{References}

1 Fontaine G, Guiraudon G, Frank R, et al. Stimulation studies and epicardial mapping in ventricular tachycardia: study of mechanism and selection for surgery. In: Kulbertus H, ed. Reentrant arrhythmias, mechanism and treatment. Lancaster: MTP Publishing, 1977:334.

2 Marcus FI, Fontaine G, Guiraudon G, et al. Right ventricular dysplasia: a report of 24 adult cases. Circulation 1982;65:384-98.

3 Frank R, Fontaine G, Guiraudon G, et al. Dysplasie ventriculaire droite arytmogene et maladie de Uhl.
Arch Mal Coeur 1982;75:361-72.

4 Higuchi S, Caglar NM, Shimada R, Yamada A, Takeshita A, Nakamura M. Sixteen-year follow-up of arrhythmogenic right ventricular dysplasia. $\mathrm{Am}$ Heart J 1984;108:1363-5.

5 Baran A, Nanda NC, Falkoff M, Barold SS, Gallagher JJ. Two-dimensional echocardiographic detection of arrhythmogenic right ventricular dysplasia. $\mathrm{Am}$ Heart $J$ 1982;103:1066-7.

6 Dungan WT, Garson A Jr, Gillette PC. Arrhythmogenic right ventricular dysplasia in children with apparently normal hearts. Am Heart J 1981; 102:745-50.

7. Rowland E, McKenna WJ, Sugrue D, Barclay R, Foale RA, Krikler DM. Ventricular tachycardia of left bundle branch block configuration in patients with isolated right ventricular dilatation. Clinical and electrophysiological features. Br Heart J 1984;51:15-24.

8 Sahn DJ, De Maria A, Kisslo J, Weyman A. Recommendations regarding quantification in $\mathrm{M}$-mode echocardiography: results of a survey of echocardiographic measurements. Circulation 1978; 58:1072-83.

9 Leitl GP, Buchanan JW, Wagner HH. Monitoring cardiac function with nuclear techniques. Am J Cardiol 1980;46:1125-32.

10 Blomström-Lundqvist C, Eneström S, Edvardsson N, Olsson B. Arrhythmogenic right ventricular dysplasia presenting with ventricular tachycardia in a father and son. Clin Cardiol 1987;10:277-85.

11 Olsson SB, Edvardsson N, Emanuelsson H, Eneström S. A case of arrhythmogenic right ventricular dysplasia with ventricular fibrillation. Clin Cardiol 1982;5:591-6.

12 Jonsell S. A method for the determination of the heart size by teleroentgenography (a heart volume index). Acta Radiol (Stockh) 1939;20:325-40.

13 Reiter MJ, Smith WM, Gallagher JJ. Clinical spectrum of ventricular tachycardia with left bundlebranch morphology. Am J Cardiol 1983;51:113-21.

14 Manyari DE, Duff HJ, Kostuk WJ, et al. Usefulness of noninvasive studies for diagnosis of right ventricular dysplasia. Am J Cardiol 1986;57:1147-53.

15 Rakovec P, Rossi L, Fontaine G, Sasel B, Markez J, Voncina D. Familial arrhythmogenic right ventricular disease. Am J Cardiol 1986;58:377-8.

16 Panidis IP, Greenspan AM, Mintz GS, Ross J. Inducible ventricular fibrillation in arrhythmogenic right ventricular dysplasia. Am Heart J 1985; 5:1067-9.

17 Brugada P, Green M, Abdolah H, Wellens HJJ. Significance of ventricular arrhythmias initiated by programmed stimulation: the importance of the type of ventricular arrhythmia induced and the number of premature stimuli required. Circulation 1984;69: 87-92.

18 Wellens HJJ, Brugada P, Stevenson WG. Programmed electrical stimulation of the heart in patients with life-threatening ventricular arrhythmias: what is the significance of induced arrhythmias and what is the correct stimulation protocol? Circulation 1985;72:1-7.

19 Foale RA, Nihoyannopoulos P, Ribeiro W, et al. Right 
ventricular abnormalities in ventricular tachycardia of right ventricular origin: relation to electrophysiological abnormalities. Br Heart $J$ 1986; 56:45-54.

20 Beerman LB, Zuberbuhler JR, Neches WH, et al. Arrhythmogenic right ventricular dysplasia associated with atrioventricular conduction disturbance. Am J Cardiol 1983;52:909-12.

21 Ruder MA, Winston SA, Davis JC, Abbott JA, Eldar M, Sheinman MM. Arrhythmogenic right ventricular dysplasia in a family. Am J Cardiol 1985; 56:799-800.

22 Strain JE, Grose RM, Factor SM, Fisher JD. Results of endomyocardial biopsy in patients with spontaneous ventricular tachycardia but without apparent structural heart disease. Circulation 1983;68: 1171-81.

23 Deal BJ, Miller SM, Scagliotti D, Prechel D, Gallastegui JL, Hariman RJ. Ventricular tachycardia in a young population without overt heart disease. Circulation 1986;73:1111-8.

24 Slama R, Leclerq JF, Coumel P. Paroxysmal ventricular tachycardia in patients with apparently normal hearts. In: Zipes DP, Jalife J, eds. Cardiac electrophysiology and arrhythmias. New York: Grune and Stratton, 1985:545.

25 Fulton DR, Chung KJ, Tabakin BS, Keane JF. Ventricular tachycardia in children without heart disease. Am J Cardiol 1985;55:1328-31.

26 Gallavardin L. Extra-systole ventriculaire a paroxysme tachycardiques prolonges. Arch Mal Coeur 1922; 15:298-306.

27 Buxton AE, Waxman HL, Marchlinski FE, Simson MB, Cassidy D, Josephsson M. Right ventricular tachycardia; clinical and electrophysiological charac- teristics. Circulation 1983;68:917-27.

28 Fontaine GH, Guiraudon G, Frank R. Intramyocardial conduction defects in patients prone to ventricular tachycardia. I. The post-excitation syndrome in sinus rhythm. In: Management of ventricular tachycardia-role of mexiletine. Amsterdam: Excerpta Medica, 1978:39-55.

29 Fontaine G, Frank R, Guiraudon G, et al. Signification des troubles de conduction intraventriculaires observes dans la dysplasie ventriculaire droite arytmogene. Arch Mal Coeur 1984;77:872-9.

30 Morgera T, Salvi A, Alberti E, Silvestri F, Camerini F. Morphological findings in apparently idiopathic ventricular tachycardia. An echocardiographic haemodynamic and histological study. Eur Heart $J$ 1985;6:323-34.

31 Manyari DE, Klein GJ, Gulamhusein S, et al. Arrhythmogenic right ventricular dysplasia: a generalised cardiomyopathy? Circulation 1983;68:251-7.

32 Webb JG, Kerr CR, Huckell VF, Mizgala HF, Ricci DR. Left ventricular abnormalities in arrhythmogenic right ventricular dysplasia. Am J Cardiol 1986;58:568-70.

33 Sevick RJ, Wyse DG. Long-term management of arrhythmogenic right ventricular dysplasia. Can Med Assoc $J$ 1983;128:418-20.

34 Guiraudon G, Fontaine G, Frank R, Leandri R, Barra $J$, Cabrol C. Surgical treatment of ventricular tachycardia guided by ventricular mapping in 23 patients without coronary artery disease. Ann Thorac Surg 1981;32:439-50.

35 Fontaine G, Guiraudon G, Frank R, Fillette F, Cabrol C, Grosgogeat Y. Surgical management of ventricular tachycardia unrelated to myocardial ischemia or infarction. Am J Cardiol 1982;49:397-410. 